\title{
CULTIVATION OF PLEUROTUS OSTREATUS MUSHROOM ON WASTE PRODUCTS AND COMPOST FOR PHENOL DEGRADATION
}

\begin{abstract}
Spaska Yaneva, Metodi Mladenov
Abstract. Remediation through application of different kinds of mushrooms is relatively limited due to different objective factors affecting the growth and development of the mushroom species. This paper presents the results of experiments performed to cultivate the Pleurotus ostreatus mushroom on substrates based on various organic wastes and composts. The mushroom mycelium blocks were transferred to soil mixtures and the period of adaptation and sporophores formation was monitored. From sporophores was isolated and purified enzyme tyrosinase, which was tested for phenol degradation activity. The obtained results, show's that the dense homogeneous blocks formed between the mycelium and the substrate can be used for the recovery of solid waste products for direct application to soils contaminated with phenol.
\end{abstract}

Key words: Pleurotus ostreatus, bioremediation, toxic compounds degradation, phenol decomposition, compost.

\section{INTRODUCTION}

The use of mushrooms as a method of bioremediation provides opportunities to clean up pollutants from the environment, primarily in soils. Pleurotus ostreatus (P. ostreatus) mushrooms are disease resistant and their cultivation does not require sophisticated control. These mushrooms are easily cultivated on a variety of nutritive substrates, including some waste products [1]. Girmay et al. [2] have reported that $P$. ostreatus mushrooms can grow on cottonseeds, paper wastes, wood saw-dust and wheat straw, with varying growth rates. The highest biological and economic yields, as well as the highest percentage of bio-efficiency of the mushrooms studied, were obtained using cotton seeds, while the lowest was the wood saw-dust.

The mycelium of Pleurotus ostreatus produce enzymes and acids degrading lignin and cellulose, which structurally resemble a variety of organic contaminants. Lignolytic mushrooms are used for the removal of aromatic pollutants and hard degradable chlorinated contaminants [3, 4]. Increasing studies indicate that mushrooms can transform many structures of pharmaceutical compounds, including anti-inflammatories, $\beta$-blockers, and antibiotics [5]. They have the ability to grow on different crude lignocellulosic substrates and over a wide range of temperatures [1]. For example the results, published from Ritota and Manzi [6] show that the mushrooms from genus Pleurotus are suitable for cultivation both in different climates and on a variety of substrates, including conifer wood and even pine needles.

There are also a number of benefits from growing Pleurotus ostreatus: utilizing the waste generated and purifying the available organic pollutants; use of the sponge for feeding animals and for extracting enzymes and medicinal compounds $[7,8]$.

In the transition to a circular economy of modern society, the focus has shifted from a vision to the creation of real policies. Under this new concept, different types of waste, including agricultural waste and household waste streams, are considered a valuable resource. Mushroom cultivation on various waste-based substrates can be sustainable economically and environmentally. This would lead not only to the production of edible and/or medicinal mushrooms, but also to a spent mushroom substrate (SMS), which can find a wide variety of applications. Fig. 1 shows the use of SMS in a circular economy according to [7].

Kh.Alananbeh et al. [9] reported on study conducted in 2014 on mushroom cultivation upon palm leaf waste mixed with other agro-waste generated. In this study, the agricultural waste used are mixed with palm leaves in different proportions with two types of additives, and the mixture from wheat straw and date palm in a 3:1 ratio shows the best results.

Phenol is a highly toxic compound that has a high degree of bioaccumulation along the food chain and has a proven negative impact on living organisms and the environment. For example, its effect on aquatic organisms is manifested even at relatively low concentrations in the range of $5-25 \mathrm{mg} / \mathrm{L}$ [10]. Therefore, its removal or neutralization into the environment poses a real challenge for researchers.

In our previous investigation, the coffee sludge as a nutrient substrate for the cultivation of Pleurotus ostreatus was used, and it was found that the mycelium was successfully developing in heavy metal contaminated soil. The efficacy of $P$. ostreatus in the absorption of $\mathrm{Cu}, \mathrm{Zn}, \mathrm{Ni}, \mathrm{Al}, \mathrm{Bi}, \mathrm{Mn}$ and $\mathrm{Fe}$ from the soil has been demonstrated [11].

No published data were found for the cultivation of fungal mycelium in contaminated soils taken from the natural environment (not created under laboratory conditions). In addition to the inclusion of various organic composts in the raw material cycle, the 
possibility of developing micellar blocks in such real contaminated soils has been explored in order to improve their properties, cleanse them from pollutants and restore equilibrium.
The purpose of current work is to cultivate a mushroom (Pleuortus ostratus) on substrates based on organic waste and compost, with the application of direct degradation of phenol in water and soil.

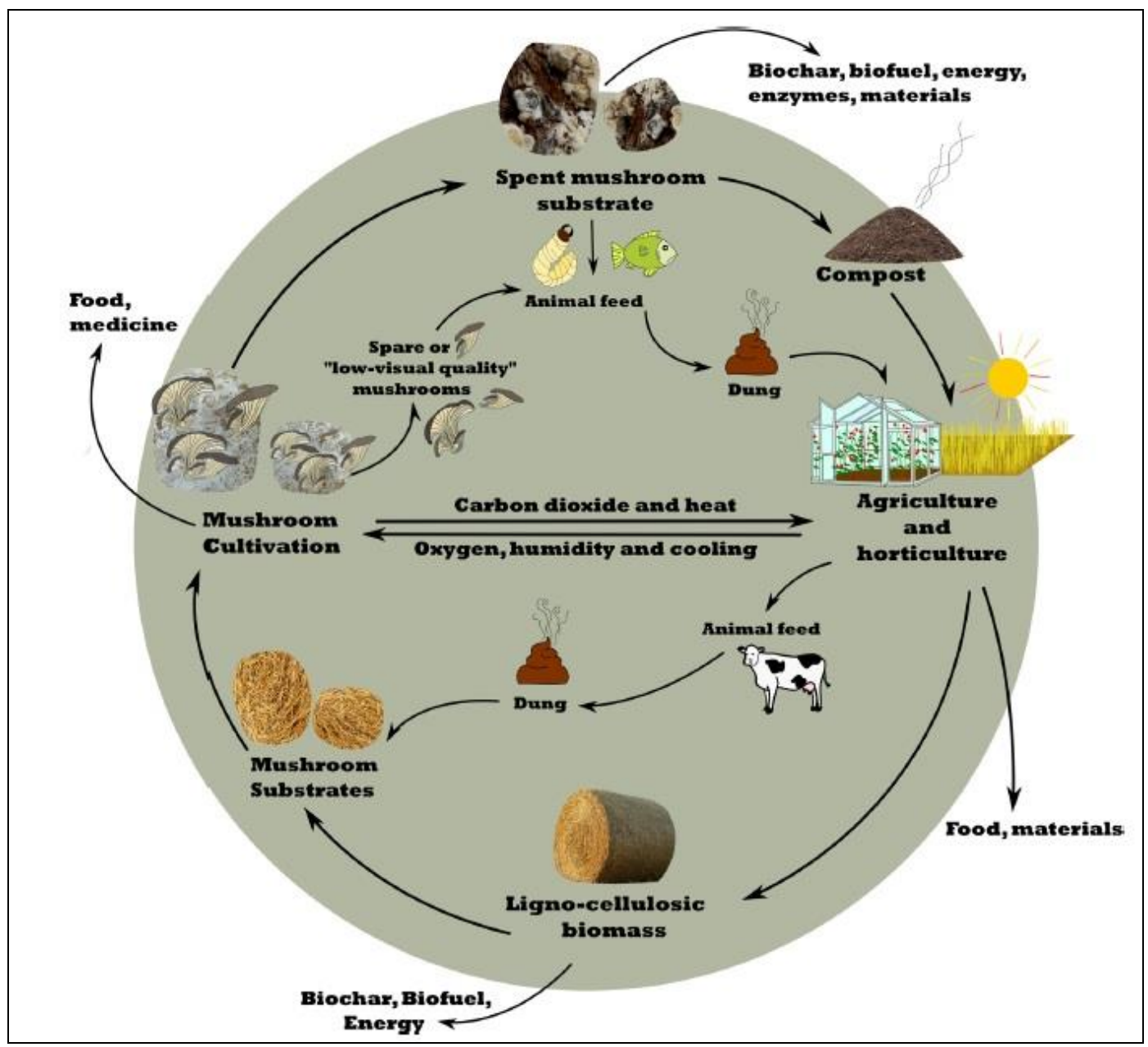

Fig. 1. Use of SMS in a circular economy [7].

\section{MATERIALS AND METHODS}

The experimental work consists three main stages:

1. Cultivation of Pleurotus ostreatus in five different substrates to form a homogeneous block of micelles

The mushroom culture was prepared according to [6] on malt extract agar medium for 7 days. Fifty gram of malt extract agar was mixed with $1 \mathrm{~L}$ of distilled water. Test tubes were corked, sterilized (at $121{ }^{\circ} \mathrm{C}$, for $30 \mathrm{~min}$ ). To obtain pure culture, a piece $(5 \mathrm{~mm} \times 5 \mathrm{~mm})$ of fleshy tissue was aseptically transferred to individual malt extract agar slants under UV fitted inoculation chamber. The cultures were incubated at $25{ }^{\circ} \mathrm{C}$ until sufficient mycelia growth. The slant culture was transferred to petri- plates and incubated at $25{ }^{\circ} \mathrm{C}$ for 7 days. Pieces of agar $(1 \mathrm{x} 1 \mathrm{~cm})$ with mycelium were transferred directly to the surface of the test substrates, evenly distributed over their surface. The content of substrate forming materials is described in detail in Table. 1. Samples were sterilized at $121{ }^{\circ} \mathrm{C}$ in an autoclave for $20 \mathrm{~min}$ and then cooled to room temperature. They are all placed in plastic containers of 1L capacity.

The moisture of the substrate used for cultivation should be $70-80 \%$ and the sterilized mixture was inoculated with previously grown pure cultures of the Pleurotus ostreatus strain. The inoculated samples were incubated in the dark at room temperature $\left(26-28^{\circ} \mathrm{C}\right)$ until complete colonization of substrates from the mycelium. 
Table 1. Raw materials used for Pleurotus ostreatus cultivation

\begin{tabular}{|c|c|c|}
\hline № & Raw materials - substrates (150 g) & Supplements (15g) \\
\hline $\mathbf{1}$ & Compost from hardwood & perlite \\
\hline $\mathbf{2}$ & Compost from conifer wood & perlite \\
\hline $\mathbf{3}$ & Compost from municipal solid wastes & perlite \\
\hline $\mathbf{4}$ & Coffee grounds & perlite \\
\hline $\mathbf{5}$ & Hardwood saw-dust & perlite \\
\hline $\mathbf{6}$ & Hardwood saw-dust & no \\
\hline
\end{tabular}

2. Laying the mycelial block in containers with soil mixtures to monitor the adaptation of the mycelium in the soil environment

For the purposes of the study, a sample of soil material was taken from a material heap at a mine for the extraction of non-ferrous metals. This soil material is characterized by a lack of organic component, low nutrient reserve $(\mathrm{N}, \mathrm{P}, \mathrm{K}, \mathrm{Ca}, \mathrm{Mg}$, $\mathrm{Na}, \mathrm{S})$ and increased concentrations of heavy metals
$(\mathrm{Cu}, \mathrm{Zn}, \mathrm{Ni}, \mathrm{Al}, \mathrm{Bi}, \mathrm{Mn}$ and $\mathrm{Fe})$. The soil material samples were pre-treated by drying, removing rock fragments and large rock specimens, crushing and sieving $(2 \mathrm{~mm})$, then preparing three mixtures with coffee sludge additives, $\mathrm{CaCl}_{2}$ and $\mathrm{CaSO}_{4} \cdot 2 \mathrm{H}_{2} \mathrm{O}$. Used for comparison and a clean sample of soil material (no additives). The resulting mycelial blocks were transferred to the pre-prepared mixtures, the composition of which is given in Table 2.

Table 2. Soil mixtures used for experiments

\begin{tabular}{|c|c|c|}
\hline № & Soil samples & amount $(\mathbf{g})$ \\
\hline 1 & Soil & 450 \\
\hline 2 & Soil and coffee grounds (1:1) & 450 \\
\hline 3 & Soil and $\mathrm{CaCl}_{2}$ & $400+50$ \\
\hline 4 & Soil and $\mathrm{CaSO}_{4} \cdot 2 \mathrm{H}_{2} \mathrm{O}$ & $400+50$ \\
\hline
\end{tabular}

The period of adaptation of the mycelial blocks involved in the mixtures and the time of sporophores formation were monitored.

3. Isolation of tyrosinase enzyme from sporophores formed and degradation of phenol as model substrate
The isolation and purification of the tyrosinase enzyme from the sporophores of Pleuortus ostreatus was performed according to the methodology described in [12]. The isolation and purification process are shown schematically in the figure below.

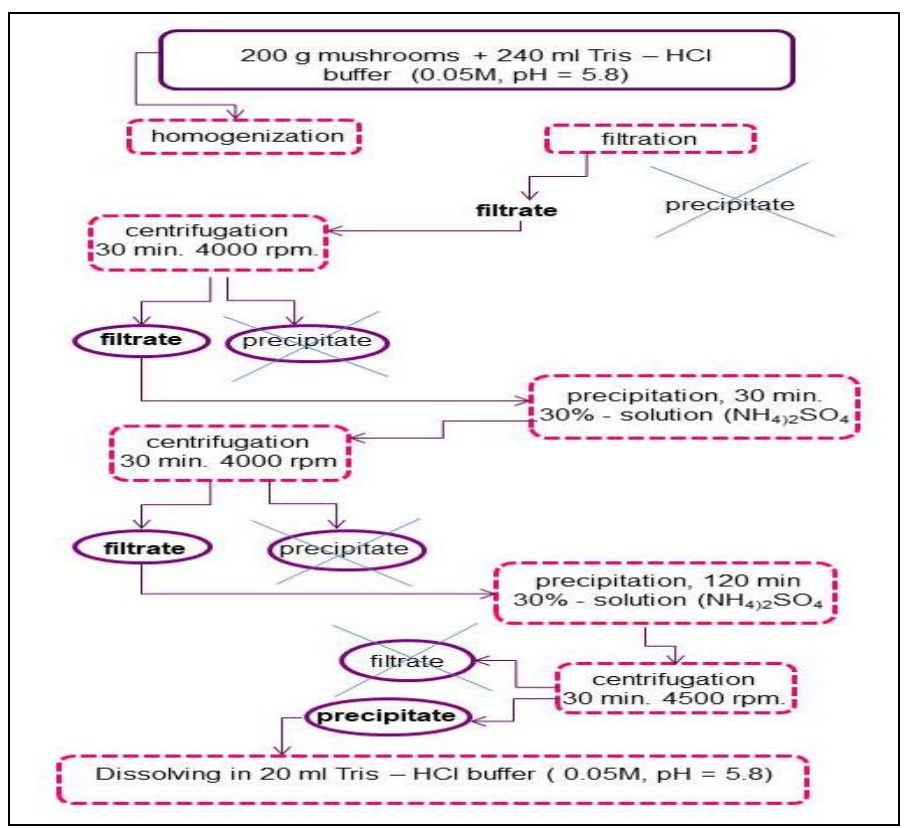

Fig. 2. Steps for isolation and purification of tyrosinase from mushroom's sporophores 
Isolated and purified tyrosinase was assayed for enzymatic activity for phenol degradation. The procedure was performed as described in [13].
The reagents used in the experimental work at this stage and their quantities are given in Table 3.

Table 3. Reagents used for phenol degradation procedure

\begin{tabular}{|c|c|c|c|}
\hline № & reactive & $\begin{array}{c}\text { control } \\
\text { sample }\end{array}$ & $\begin{array}{c}\text { isolated } \\
\text { tyrosinase }\end{array}$ \\
\hline 1 & $\begin{array}{c}\text { phosphate buffer } \\
0.5 \mathrm{M} \mathrm{KH}_{2} \mathrm{PO}_{4}, 0.6 \mathrm{M} \mathrm{K}_{2} \mathrm{HPO}_{4} \\
(\mathrm{pH}=7.9)\end{array}$ & $65 \mu \mathrm{l}$ & $65 \mu \mathrm{l}$ \\
\hline 2 & $0.5 \mathrm{M} \mathrm{NH}_{4} \mathrm{OH}$ & $75 \mu \mathrm{l}$ & $75 \mu \mathrm{l}$ \\
\hline 3 & $\begin{array}{c}100 \mathrm{mM} \\
\text { 4-aminoantipyrine }\end{array}$ & $30 \mu \mathrm{l}$ & $30 \mu \mathrm{l}$ \\
\hline 4 & $250 \mathrm{mM}$ potassium ferricyanide & $30 \mu \mathrm{l}$ & $30 \mu \mathrm{l}$ \\
\hline 5 & phenol in d. water & $2800 \mu \mathrm{l}$ & $2800 \mu \mathrm{l}$ \\
\hline 6 & enzyme solution & $100 \mu \mathrm{ld}$ water & $100 \mu \mathrm{l}$ \\
\hline
\end{tabular}

Phenol with concentrations of $1.2 \mu \mathrm{g} / \mathrm{ml}, 1.6$ $\mu \mathrm{g} / \mathrm{ml}$ and $2.0 \mu \mathrm{g} / \mathrm{ml}$ for a period of 72 hours was used for the experiment. The measurements were performed with a spectrophotometer VWR634-6001, UV-1600PC (Germany) at a wavelength $\lambda=500 \mathrm{~nm}$.

The rate of degradation of phenol in wastewater was monitored and samples were photometrically determined at intervals after plating, at 1, 3, 6, 12, 18, 24, and 72 hours.

\section{RESULTS AND DISSCUSION}

In the present Pleuortus ostreatus cultivation experiment, different substrates were used: deciduous wood compost, coniferous wood compost, solid waste compost, coffee sludge, and deciduous wood chips. Although in its natural environment, Pleuorotus ostreatus grows on deciduous wood, the species has proven to be adaptable to a variety of substrates, including coniferous compost [14]. The coniferous wood compost used, nonspecific as the natural environment of $P$. ostreatus development, is the probable reason, despite the formation of a stable mycelial block in the starting substrates, to not observe the appearance of sporophores after its transfer to soil mixtures.

Cultivation of $P$. ostreatus based on waste coffee residues (WCR) from coffee consumption is a new way of recycling this waste product. The presence of caffeine inhibits the growth of micelles on agar and in liquid culture in the laboratory. Carrasco-Cabrera reported that elevated WCR levels in the WCR/sawdust substrate also slow the growth of the mycelium and delay or prevent fruiting during commercial cultivation. The timing of mycelium formation in the present experiment coincides with that reported in [15] - 18 days.

Table 4 presents the time data for the formation of micelles on different nutrient media. The same table shows the time for the formation of sporophores after transferring the mycelial block to soil mixtures.

Table 4. Time for colonization and fruiting (in days)

\begin{tabular}{|l|l|c|c|}
\hline № & \multicolumn{1}{|c|}{ Raw materials (substrates) } & $\begin{array}{c}\text { Complete colonization } \\
\text { of the substrate }\end{array}$ & $\begin{array}{c}\text { Fruiting after transfer of } \\
\text { the mycelium into the soil } \\
\text { mixtures }\end{array}$ \\
\hline $\mathbf{1}$ & Compost from hardwood & 17 & 14 \\
\hline $\mathbf{2}$ & Compost from conifer wood & 25 & no fruiting \\
\hline $\mathbf{3}$ & Compost from municipal solid wastes & 25 & 14 \\
\hline $\mathbf{4}$ & Coffee grounds (waste coffee residues) & 18 & 12 \\
\hline $\mathbf{5}$ & Hardwood saw-dust & 20 & 15 \\
\hline $\mathbf{6}$ & Hardwood saw-dust without perlite & 22 & 16 \\
\hline
\end{tabular}


The cultivation practice of $P$. ostreatus shows that 2-3 mushroom harvests are harvested, after which the spent nutrient substrate is discarded. Koshy et al reported that this substrate can be used effectively to remove phenol from wastewater up to $48 \%$ after 1 day of treatment. The process guarantees the double benefit of the growing production of mushrooms with nutritional/healing properties and using the spent substrate for bioremediation. The process also offers a sustainable solution for the management of solid wastes from spent mushroom substrate [10].

In this regard, the collected sporophores of Pleurotus ostreatus were used to isolate and purify tyrosinase and were applied to the subsequent degradation of phenol. The results presented in Fig. 3 show that at the twelfth hour of treatment, a $42 \%$ degradation rate of phenol was observed, at the twenty-fourth hour - 58\%, and at the seventy-second hour, more than $71 \%$ degradation was achieved in the sample with concentration $1.2 \mu \mathrm{g} / \mathrm{ml}$. At higher concentrations of phenol $(1.6 \mu \mathrm{g} / \mathrm{ml}$ and $2.0 \mu \mathrm{g} / \mathrm{ml})$, its degradation rate does not exceed $40-42 \%$ and remains almost constant for the time between the twenty-fourth and seventy-second hours. The likely reason for this is the high concentration of pollutants in the soil that exert an inhibitory effect on enzyme activity. On Fig. 3 the correlation between the degraded phenols versus time in different phenol concentrations are show.

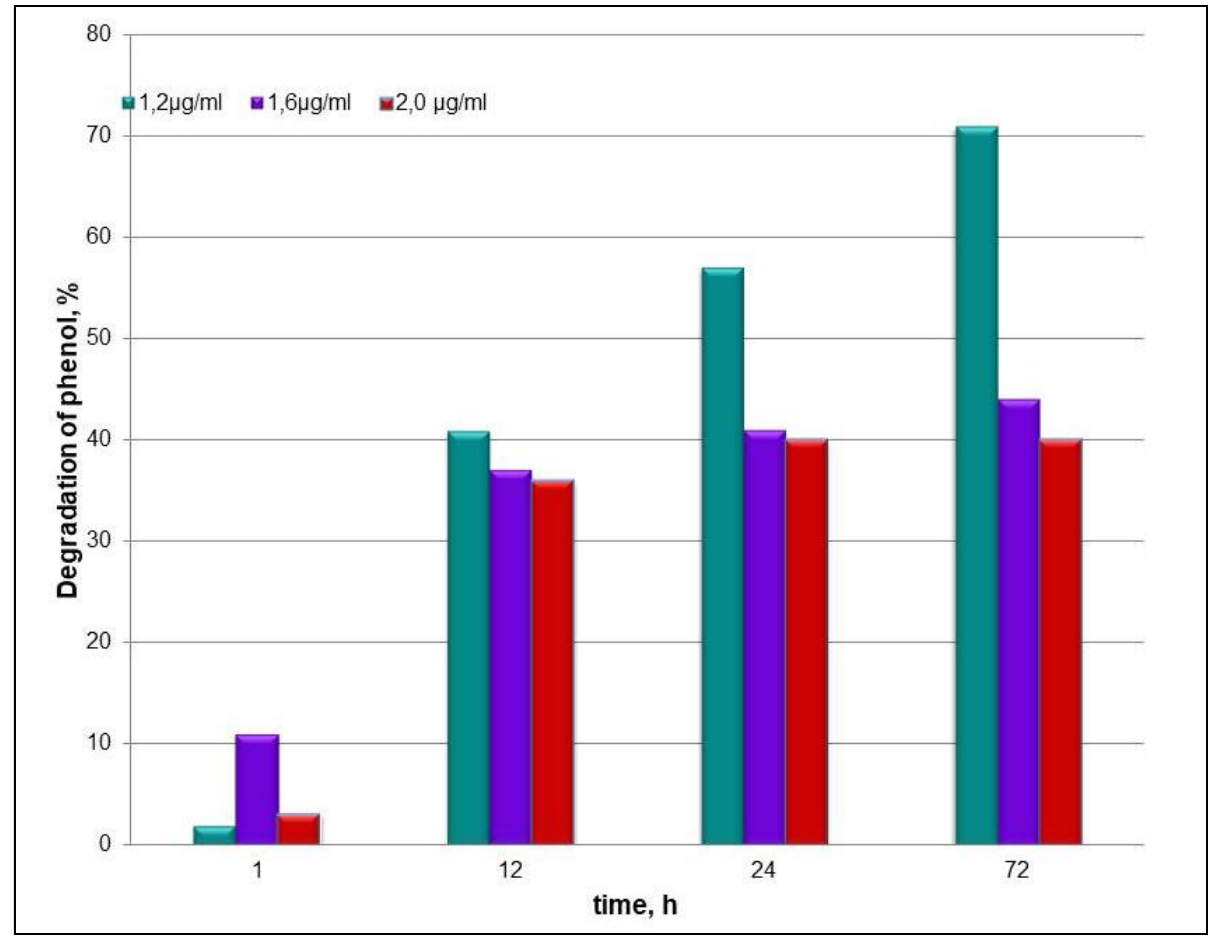

Fig. 3. Correlation between the percentages degraded phenol versus time. Phenol concentration $1.2 \mu \mathrm{g} / \mathrm{ml}, 1.6 \mu \mathrm{g} / \mathrm{ml}$ and $2.0 \mu \mathrm{g} / \mathrm{ml}$.

The results obtained correspond to those reported in [16], where a phenolic degradation rate of $100 \%$ was achieved under similar experimental conditions. The probable reason for the lower percentage of degraded phenol in the experiment was that the mycelial blocks had previously undergone an adaptation step in soil samples, which reduced the enzymatic activity in the fungi.

There are numerous studies using microremediation at artificially polluted organic pollutants, but the significance of studies under non-sterile conditions, with real soil/wastewater contamination, and results can be transferred to the field using biostimulation, bioaggregation or both [17]. In this regard, the experimental results of the study showed the possibility of cultivating P. ostreatus mushroom fungus in soil material taken from the environment containing elevated concentrations of heavy metals, as well as growth the mycelium in such an environment in order to improve the properties and purification from pollutants.

\section{CONCLUSIONS}

Based on the experiments performed, the following conclusions can be summarized. Pleuortus ostreatus mycelium was successfully cultivated on five 
different food substrates: compost from hardwood, compost from conifer wood, compost from municipality solid wastes, coffee sludge (waste coffee residues) and hardwood saw-dust.

The formed blocks of mushroom micelles were successfully introduced into mixtures based on soil material characterized by low fertility, poor nutritional content and high content of heavy metals, with fruiting times between 12 and 16 days (except for compost obtained from coniferous wood).

It has been found that the addition of calcium chloride and calcium sulphate to the mixture does not affect the period of adaptation of the micelles and the time of sporophores formation.

Tyrosinase isolated and purified from mushroom bodies showed high phenol degradation activity $71 \%$ at the seventy-second hour.

\section{REFERENCES}

1. Performance of Pleurotus ostreatus mushroom grown on maize stalk residues supplemented with various levels of maize flour and wheat bran, Food Sci. Technol., Campinas., 36, 4, 2016 598-605.

2. Z. Girmay, W. Gorems, G. Birhanu and S. Zewdie, Growth and yield performance of Pleurotus ostreatus (Jacq. Fr.) Kumm (oyster mushroom) on different substrates, AMB Expr., 6:87, 2016, 1-7, DOI 10.1186/s13568-016-0265-1.

3. C. Pinedo-Rivilla, J. Aleu and I. G. Collado, Pollutants Biodegradation by Fungi, Current Organic Chemistry, 13, 2009, 1194-1214.

4. A. T. Lawal, Polycyclic aromatic hydrocarbons. A review, Cogent Environmental Science 3, 2017, 1339841, 1-89.

5. D. R. Olicón-Hernández, J. González-López, Elisabet Aranda, Overview on the Biochemical Potential of Filamentous Fungi to Degrade Pharmaceutical Compounds, Front. Microbiol., 20, 8, 2017, 1-17.

6. M. Ritota and P. Manzi, Pleurotus spp. Cultivation on Different Agri-Food By-Products: Example of Biotechnological Application, Review, Sustainability, 11, 2019, 5049.

7. Daniel Grim, Han A. B. Wösten, Mushroom cultivation in the circular economy, Applied Microbiology and Biotechnology, 102, 2018, 7795-7803.

8. M. F. Mohamed, E. F. S. Refaei, M. M. A. Abdalla, S. H. Abdelgalil, Fruiting bodies yield of

\section{Assist. Prof. PhD Spaska Yaneva}

University of Chemical Technology and Metallurgy, Department Fundamentals of Chemical Technology 8 St. Kliment Ohridski blvd.

Sofia, 1000, Bulgaria

e-mail: sp_yaneva@uctm.edu oyster mushroom (Pleurotus columbinus) as affected by different portions of compost in the substrate, Int J Recycl Org Waste Agricult, 5, 2016 281-288.

9. K. M. Alananbeh, N. A. Bouqellah, N. S. Al Kaff, Cultivation of oyster mushroom Pleurotus ostreatus on date-palm leaves mixed with other agro-wastes in Saudi Arabia, Saudi Journal of Biological Sciences, 21, 2014, 616-625.

10. J. Koshy, N. Chandran and P. Nambisan, Biodegradation of phenol using spent substrate of Pleurotus sp., World Journal of Pharmacy and Pharmaceutical Sciences, 1, 2, 2012, 656-661.

11. M. Mladenov, S. Yaneva, D. Kolchakoba, Adsorption of heavy metals from contaminated soils using Oyster mushroom (Pleurotus ostreatus), Ecological Engineering and Environment protection, 4, 2017, 24-29.

12. P. Velichkova, D. Marinkova, S. Yaneva, L. Yotova, Annuaire de l'Université de Sofia "St. Kliment Ohridski", Faculte de Biologie, 100,4, 2015, 70-75.

13. E. Wharfe, R. Jarvis, C. Winder, A. Whiteley and R. Goodacre, Fourier transform infrared spectroscopy as a metabolite fingerprinting tool for monitoring the phenotypic changes in complex bacterial communities capable of degrading phenol, Environmental Microbiology, 12,12, 2010, 3253-3263.

14. G. Mata, J. A. Pérez-Torres, R. Medel, R. P.-Merlo, D. Salmones, Culture of Pleurotus ostreatus in pine shavings: isolation of strains and evaluation of their productivity, Madera y Bosques, 25, 2, 2019, 1-13.

15. C.P. Carrasco-Cabrera, T.L. Bell, M.A. Kertesz, Caffeine metabolism during cultivation of oyster mushroom (Pleurotus ostreatus) with spent coffee grounds, Appl Microbiol Biotechnol. 103(14), 2019, 5831-5841.

16. V. A. Edalli and C. M. Kamanavalli Removal of phenolic compounds by mushroom polyphenol oxidase from Pleurotus species, An International Quarterly Journal of Environmental Science, 4 (1), 2010, 89-92.

17. A. M. Q. López, A. L. dos S. Silva e E. C. L. dos Santos, The fungal ability for biobleaching/ biopulping/bioremediation of lignin-like compounds of agro-industrial raw material, Quim. Nova, 40, 8, 2017, 916-931.

\section{Corresponding author: \\ Assist. Prof. PhD, Metodi Mladenov}

University of Chemical Technology and Metallurgy

Department Engineering Ecology

8 St. Kliment Ohridski blvd.

Sofia, 1000, Bulgaria,

e-mail:mladenov@uctm.edu 